\title{
FWD quality assurance in Germany
}

\author{
D. Jansen \\ Federal Highway Research Institute - BASt, Bergisch Gladbach, Germany
}

\begin{abstract}
The importance of bearing capacity measurements for structural assessment is increasing worldwide. The establishment of quality assurance procedures is therefore all the more important. As a rule, these include self-monitoring by the operator and calibration of the measuring equipment at the manufacturer's premises or at calibration centers. A complete quality assurance includes, in addition to the inspection and calibration of individual devices and device components, the participation in comparative investigations. For the Falling Weight Deflectometer (FWD), comparative measurements were established in Germany on the basis of international existing comparative tests and guidelines. The measurements take place annually on the premises of the Federal Highway Research Institute (BASt) according to a fixed schedule. In addition to checking the comparability of the deflection measurement, the repeatability and the temperature measuring equipment and the FWD setups are also checked. Furthermore, the annual event enables the important exchange between the FWD operators, which in turn is also useful for quality assurance.
\end{abstract}

Keywords: FWD, bearing capacity, comparison, quality

\section{INTRODUCTION}

The first Falling Weight Deflectometers (FWD) were put into operation in Germany in the early 1990s. The scientific introduction took place in 1996 (Straube, E., Beckedahl, H., \& Huertgen, H., 1996). A series of working papers on the planning, execution and evaluation of bearing capacity measurements were and are being prepared by the bearing capacity committee of the German Research Association for Roads and Transport (FGSV).

In the FWD related working paper (FGSV, 2008) recommendations are given for internal and external monitoring of the measuring equipment following the recommendations of COST Action 336 (European Commission, 2005), which are mainly the device calibration and check up by the manufacture and repeatability tests by the operator/owner in his own responsibility. Also, the execution of interlaboratory tests is recommended: "A central test centre will be set up to check the repeatability and reproducibility of test results of the FWD (interlaboratory tests) used in Germany." The establishment of such a central test center has not been carried out for a long time. However, the results of comparable international interlaboratory comparisons and comparative measurements organized from time to time by individual groups show that the permanent organization of such comparative measurements is an essential element of quality assurance.

The Federal Highway Research Institute (BASt), in its role as quality assurance agency for a number of measurement procedures used in the road sector and as a client for FWD measurements within the framework of research projects, has had a great interest in establishing comparative measurements for FWD in Germany. Since such comparative measurements 
have been established internationally for many years, the experience gained from these projects was used in the planning of the comparative measurements. In particular, the experience gained in the Netherlands was used (Van Gurp, 2013), which was also included in the report on COST Action 336 (European Commission, 2005). In 2015 the first comparative measurements as a start of new series have been conducted at BASt premises.

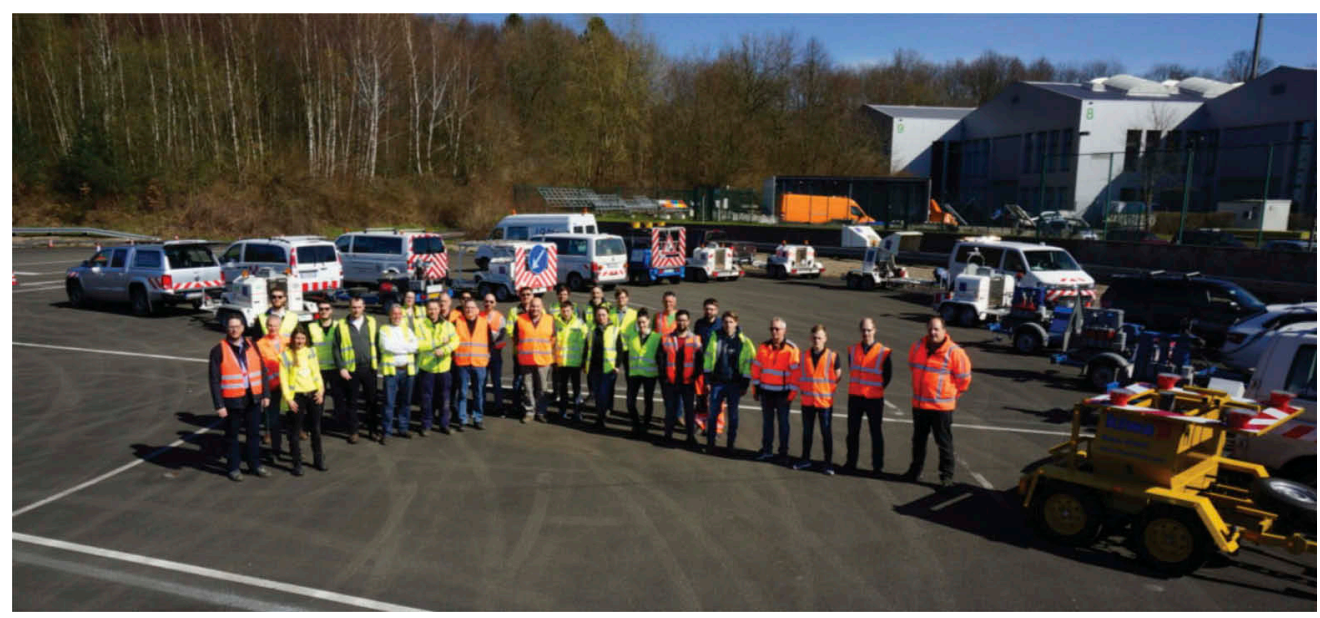

Figure 1. Participants of 2019 event.

\section{HISTORY OF COMPARATIVE EVENTS}

As said the first of a new series of comparative event as has been performed in late 2015 followed by a second event in late 2016. At the request of the participants, the event then was moved to spring, i.e. virtually shortly before the start of the measuring season. With this the third event has been performed in early 2018, followed by the fourth in early 2019 (Figure 1). The 2020 event has been cancelled a view days before due to the worldwide COVID-19 epidemic. A new event was planned for March 2021 but will also be postponed to 2022 .

Table 1. History of comparative events.

\begin{tabular}{|c|c|c|c|}
\hline $\mathrm{Nr}$. & Year & FWD/HWD & Participants \\
\hline 1 & 2015 & $\begin{array}{l}\text { 4x Sweco } \\
\text { 1x Dynatest }\end{array}$ & 5x Germany \\
\hline 2 & 2016 & $\begin{array}{l}\text { 4x Sweco } \\
\text { 2x Dynatest }\end{array}$ & 5x Germany \\
\hline 3 & 2018 & $\begin{array}{l}\text { 6x Sweco } \\
\text { 2x Dynatest }\end{array}$ & $\begin{array}{l}\text { 7x Germany } \\
\text { 1x Belgium }\end{array}$ \\
\hline 4 & 2019 & $\begin{array}{l}\text { 8x Sweco } \\
6 x \text { Dynatest }\end{array}$ & $\begin{array}{l}\text { 7x Germany } \\
\text { 1x Belgium } \\
\text { 1x Netherlands } \\
\text { 2x Denmark } \\
\text { 1x Lithuania } \\
\text { 1x Estonia }\end{array}$ \\
\hline- & 2020 cancelled & $\begin{array}{l}8 x \text { Sweco } \\
10 x \text { Dynatest }\end{array}$ & $\begin{array}{l}\text { 8x Germany } \\
\text { 1x Belgium } \\
\text { 3x Netherlands } \\
\text { 2x Denmark } \\
\text { 3x Poland } \\
\text { 1x Switzerland }\end{array}$ \\
\hline
\end{tabular}


With the years the number of participating companies increased. The event is open to everybody; therefore, the event has turned into an international event. Table 1 gives an overview of the events and participants.

Since the evaluation and assessment of the comparative measurements are essentially based on statistics, the highest possible number of participants has a quality-enhancing effect on the event.

\section{TEST SETUP}

The design of the experimental programme is closely aligned with the European consensus elaborated in COST Action 336. The experimental program pursues the following core points:

- Examination of repeatability (each FWD separately),

- Examination of comparability (comparison between the FWDs, also known as reproducibility),

- Examination of the load pulse by evaluation of the time history data as well as

- Investigation of the precision of temperature measurements.

\subsection{General setup}

In order to act as independently as possible from the aspects of traffic safety, only measuring points on the BASt site will be considered. To a certain extent, this can ensure that repeated measurements are carried out in the coming years in the same situation. A total of 21 measurement points are available per measurement round. Two measuring points are located on the model road in test hall 9, 15 measuring points on the open area of the vehicle technical test facility (FTVA) and its access road as well as four further measuring points on the visitor parking lot. Figure 2 shows a map of the situation. Table 2 shows the with the help of GPR measurements determined asphalt thicknesses for area of interest. Figure 3 shows the mean deflections (load centre deflection and deflection at $1.800 \mathrm{~mm}$ from load centre) of all selected test points. These data are only to understand the full test setup and will not be used for the interpretation of results.

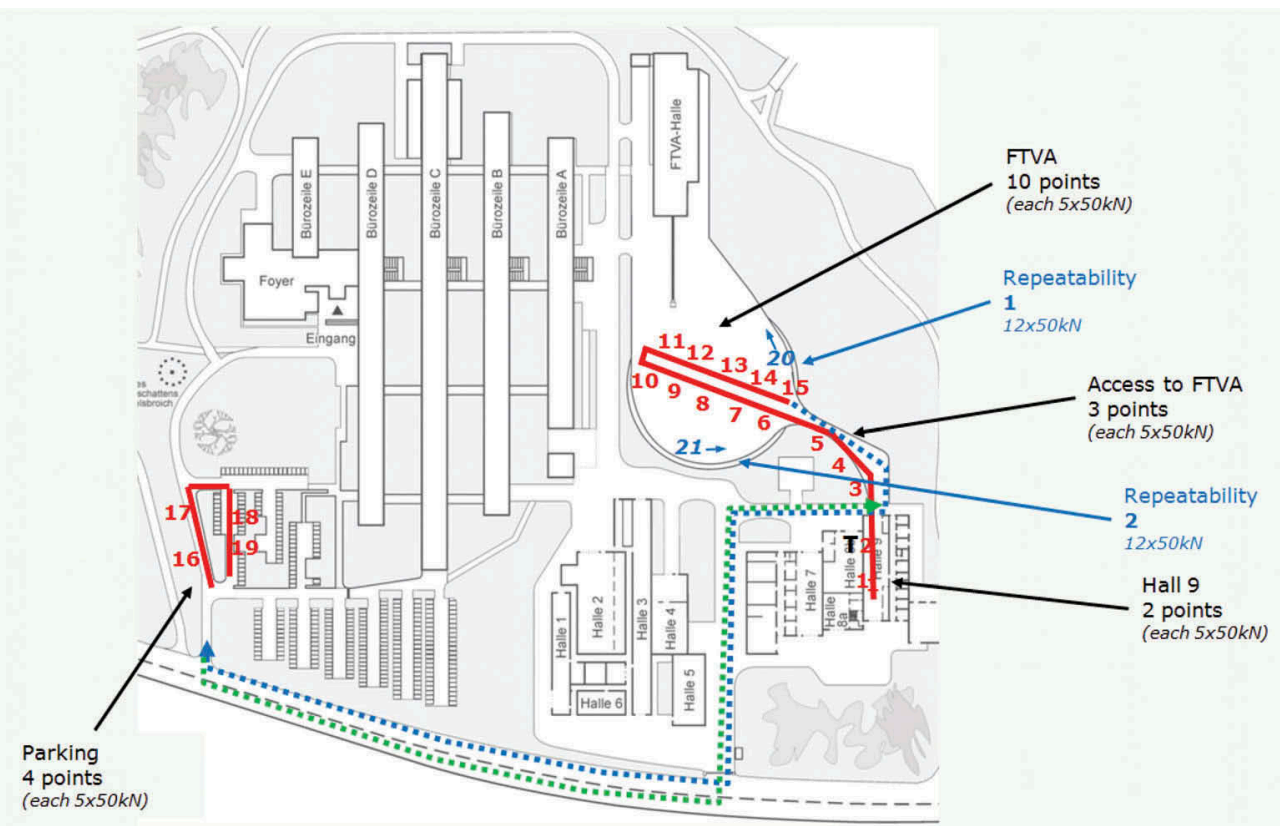

Figure 2. Situation map. 
Table 2. Asphalt thickness at measuring points.

\begin{tabular}{lll}
\hline measuring point $\mathrm{nr}$. & location & thickness of asphalt $[\mathrm{cm}]$ \\
\hline 1 & hall 9 & ca. $26 \mathrm{~cm}($ on $15 \mathrm{~cm}$ hydraulic bound base $)$ \\
2 & hall 9 & ca. $12 \mathrm{~cm}$ \\
$3-5$ & FTVA & ca. $30 \mathrm{~cm}$ \\
$6-15$ & FTVA & ca. $18 \mathrm{~cm}^{1)}$ \\
16 & parking & ca. $20 \mathrm{~cm}^{1)}$ \\
17 & parking & ca. $17 \mathrm{~cm}^{1)}$ \\
18 & parking & ca. $17 \mathrm{~cm}^{1)}$ \\
19 & parking & ca. $20 \mathrm{~cm}^{1)}$ \\
$20-21$ & FTVA & ca. $30 \mathrm{~cm}$ \\
\hline
\end{tabular}

1) from GPR

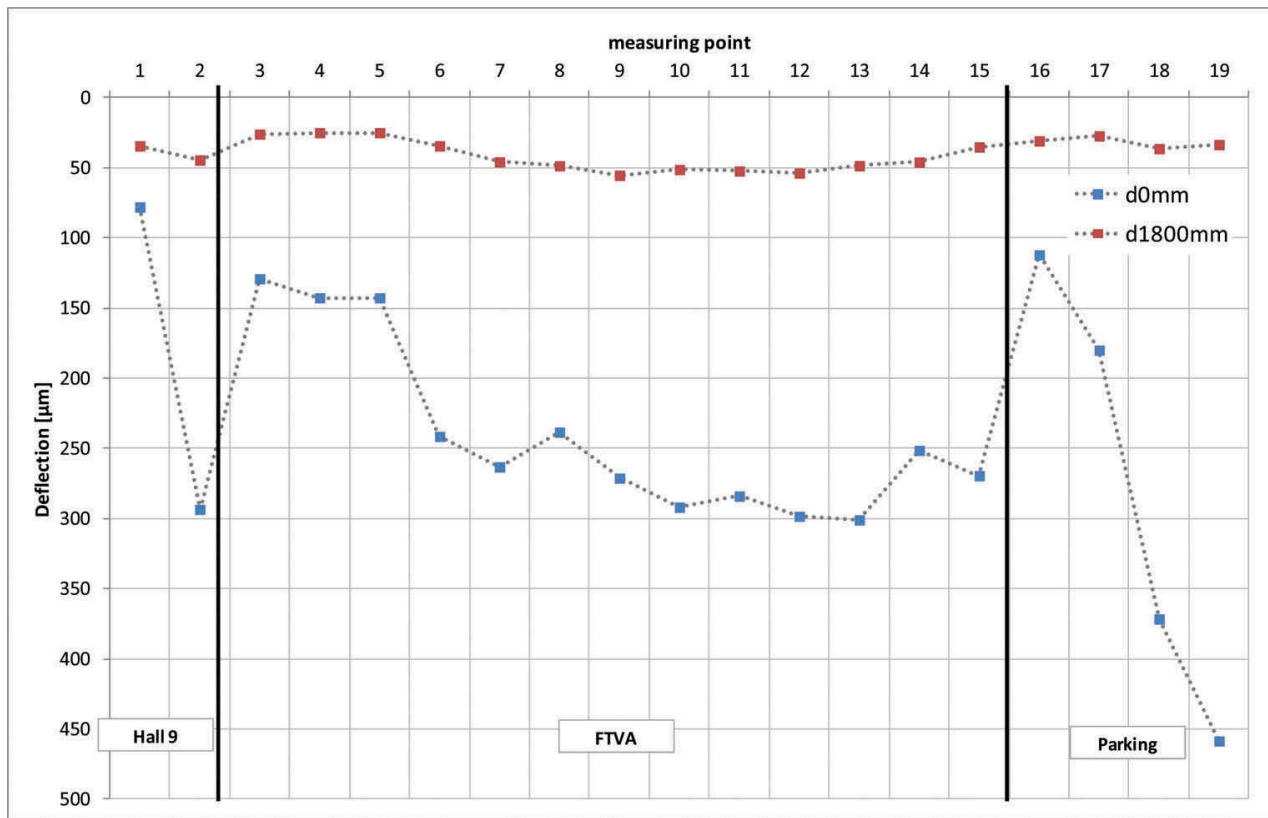

Figure 3. Mean (reference) deflections of test points.

The position of the load plate is marked beforehand at all measuring points with a circle, diameter $40 \mathrm{~cm}$. In addition, cones are set up, at which the left side of the vehicle has to be driven closely past, so that the alignment of the geophone beam is comparable.

In general, the FWDs should be equipped in accordance with the FGSV Working Paper Bearing Capacity, Part B.2 (FGSV, 2008) and brought into operational readiness as for the performance of regular measurements. These and additional requirements are given in Table 3 and will be given to the participants a few weeks before their arrival. In addition, a device audit will be carried out in which questions are asked about the model type and number, year of construction, number of geophones and their positions, number and positions of temperature recordings and other equipment features.

After the arrival of all participants, a short presentation of the process planning is be given by the test supervisor. The different test setups, the position of the measuring points and general information are presented and discussed. Each participant receives a folder with the compilation of all information and a documentation sheet (logbook) for each measurement round, which also clearly showed the measurement sequences and the associated test setups. 
Table 3. General equipment requirements.

\begin{tabular}{ll}
\hline Geophone positions & $0-200-300-450-600-900-1.200-1.500-1.800 \mathrm{~mm}$ \\
Load pulse & target load $=50 \mathrm{kN} / \mathrm{load}$ pulse duration between 25 and $30 \mathrm{~ms}$ \\
Time history & recording should be activated \\
Filtering & Peak smoothing and Cut-Off frequency at $60 \mathrm{~Hz}$ activated \\
GPS & if available activated, used only for plausibility checks \\
Temperatures & air and surface temperature (if available) plus asphalt temperatur probe equipment \\
System time & will be synchronized with the time of the test supervisor \\
\hline
\end{tabular}

The order of the FWDs among each other is determined, if possible, on the basis of existing experience in such a way that slow FWDs line up at the back. If even more FWDs participate, it is planned to introduce a staggered start at different measuring points in order to optimize the timing of the sequence.

At each event two measurement rounds are carried out, one in the morning and one in the afternoon. After each round, the operators are asked to export their results to a pre-agreed file format (txt, fwd or $\mathrm{f} 25$ format) and hand them over to the test leaders. Before the second test round starts the preliminary assessed data of the first round is presented to all participants. Based on this the operators have the chance to do modifications at their system if needed. Normally, however, no changes are made.

The detailed assessment is done shortly after the event. The results are summarized in a report and together with a certificate of participation given to the participants. In order to safeguard the economic interests of the FWD operators, the results of the comparison measurements are shown anonymously. The respective FWD operators are informed of the coding for their FWD with the notification of the results.

\subsection{Repeatability}

According to (FGSV, 2008) and (European Commission, 2005), a distinction must be made between short- and long-term repeatability tests. In the short-term repeatability test, the load plate remains on the ground, whereas in the long-term repeatability test, the measuring point is approached several times (at longer intervals). The object of the comparative investigations is the examination of the short-term repeatability.

Two measuring points are determined to check the repeatability. At these measuring points 12 load strokes with $50 \mathrm{kN}$ each (target value) are carried out. The load plate must not be lifted. Although only the last ten load strokes are evaluated, all load strokes are to be stored.

\subsection{Comparability}

To check comparability (reproducibility), 19 measuring points are selected. At each of these measuring points, five load strokes of $50 \mathrm{kN}$ each (target value) are performed. The load plate must not be lifted. Although only the last four load strokes were evaluated, all load strokes are to be stored.

\subsection{Examination of load pulse}

In order to investigate the load pulse, it is required to record the time history data at all measuring points.

\subsection{Temperature measurements}

Each FWD operator is asked to use all available measuring instruments for temperature measurement. Typically, these are: 
- air temperature (mounted on the FWD),

- surface temperature (mounted on the FWD or hand-held unit) and

- asphalt body temperature (mounted on the FWD or hand-held unit).

For the adjustment of the measuring instruments for asphalt body temperature measurement, a controlled temperature water bath is set up at one of the measuring points. The water bath temperature is set low in the morning and high in the afternoon. As a reference, the continuous measurement is carried out with a calibrated external temperature logger.

In addition, temperature loggers are installed at two measuring points to record the surface temperature.

\section{EVALUATION}

In the following the evaluation methodology and results are shown and discussed. Exemplarily, the results of one event each are presented.

\subsection{Repeatability}

Repeatability (here short-term repeatability, see above) occurs when an FWD at the same measuring point without lifting the load plate, operated by the same person, produces reproducible results with several load drops. To evaluate the repeatability, the last 10 load drops are each normalized to $50 \mathrm{kN}$. The mean value and the standard deviation of the 10 load drops are then determined. Repeatability is given if the standard deviation is less than or equal to $2 \mu \mathrm{m}$ or less than or equal to the sum of $1.0 \mu \mathrm{m}$ and $0.75 \%$ of the mean value (whichever is greater) (European Commission, 2005) (Van Gurp, 2013).

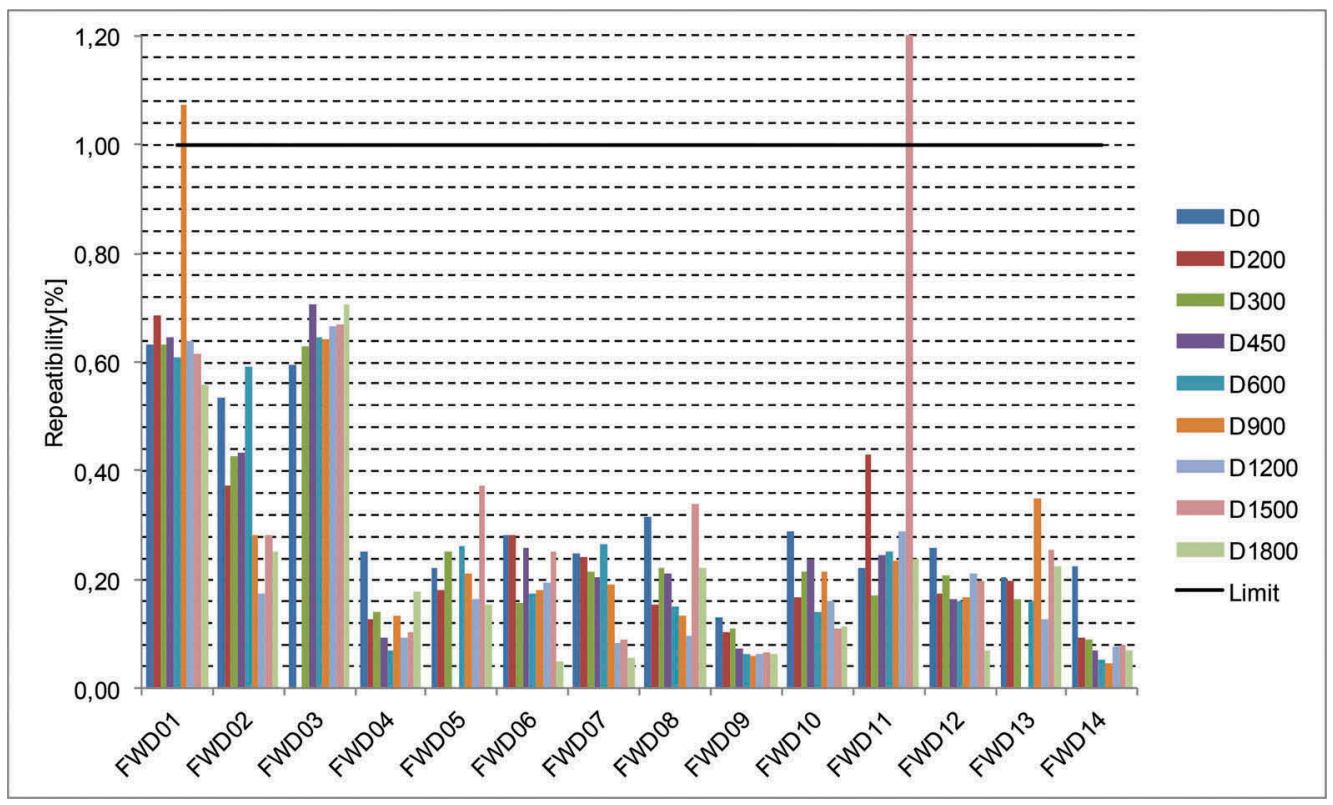

Figure 4. Results of repeatability check. 
Figure 4 represents the relative comparison of the results of a repeatability test, where the value 1.0 represents the relative limit (the smaller the value, the better). The missing data bars are due to different arrangements of the geophones. Usually this criterion is very good fulfilled by all FWDs. Deviations from this usually led to the replacement of a geophone identified as defective and a self-check by the operator/ owner afterwards.

\subsection{Comparability}

Comparability (reproducibility) exists when different FWDs, operated by different persons, produce comparable measurement results at identical measurement points. The measurements must also be carried out under identical conditions. Since the FWD visit each measuring point per measuring round in a short period of time, identical conditions are to be assumed. A cross-check will be done based on the recorded surface temperature.

The basis for a comparative assessment is the determination of a requirement level. In the case of comparative investigations, this is a 'comparison bowl' per measuring point. The comparison bowl is formed from the measured values of all FWDs and must be determined anew for each comparative study due to changing conditions. It should be noted that the comparison bowl is not an absolute reference. The following procedure was used to determine the comparison bowl and for the subsequent evaluation (European Commission, 2005) (Van Gurp, 2013):

1. normalization of the load impact 2 to 5 to $50 \mathrm{kN}$

2. calculation of the comparison bowl by averaging the load normalized deflections per geophone position of all FWDs, whereby the highest and lowest values are excluded

3. calculation of the standard deviation of the comparison bowl from the load normalized deflections per geophone position of all FWDs, whereby the highest and lowest values are excluded

4. calculation of the mean values of the load normalized deflections per geophone position and per FWD

5. check for each FWD and each geophone position whether the mean value (from 4.) lies within the range of the comparison bowl (from 2.) \pm the standard deviation (from 3.)

6. calculation of correction factors for each geophone position from the ratio of the mean value (from 4.) and the comparison bowl (from 2.)

7. calculation of correction factors for each FWD from the mean of the correction factors (from 6.)

Figure 5 Shows a typical distribution of correction factors. Again, most times these criteria are fulfilled or lead to repair, new calibration or part replacement.

\subsection{Load impulse}

The pulse durations for most FWDs range from 25 to $30 \mathrm{~ms}$. Pulse durations of up to $35 \mathrm{~ms}$ have been observed sometimes and can sometimes be connected to noticeable results at the other quality checks. If necessary the operators are recommended to check and adjust the pulse durations. At the first events the load impulse, i.e. the representation of the shape of the load impulse has been plotted and the energy input as an integral over time has been calculated. Figure 6 and 7 show some typical results. It is under discussion if the so given information gives a benefit to the comparison measurements since the time history assessment needs a lot of effort. However, the raw data are available and can be evaluated on request. 


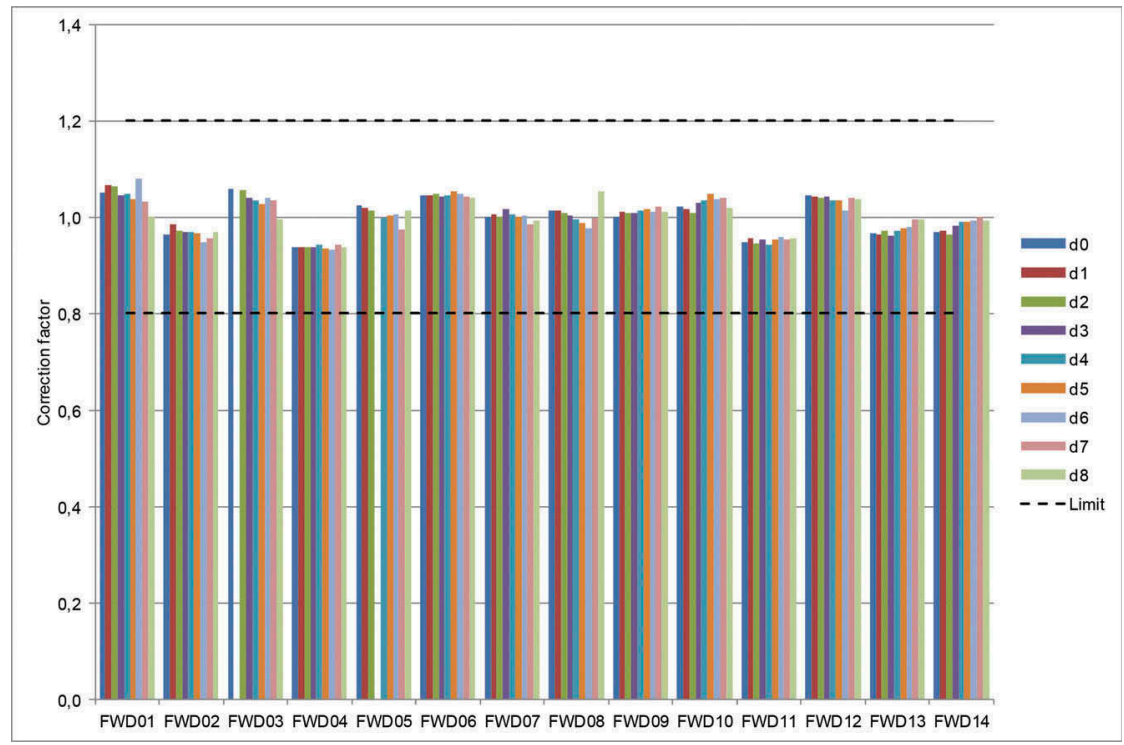

Figure 5. Calculated correction factors for each geophone of each FWD.

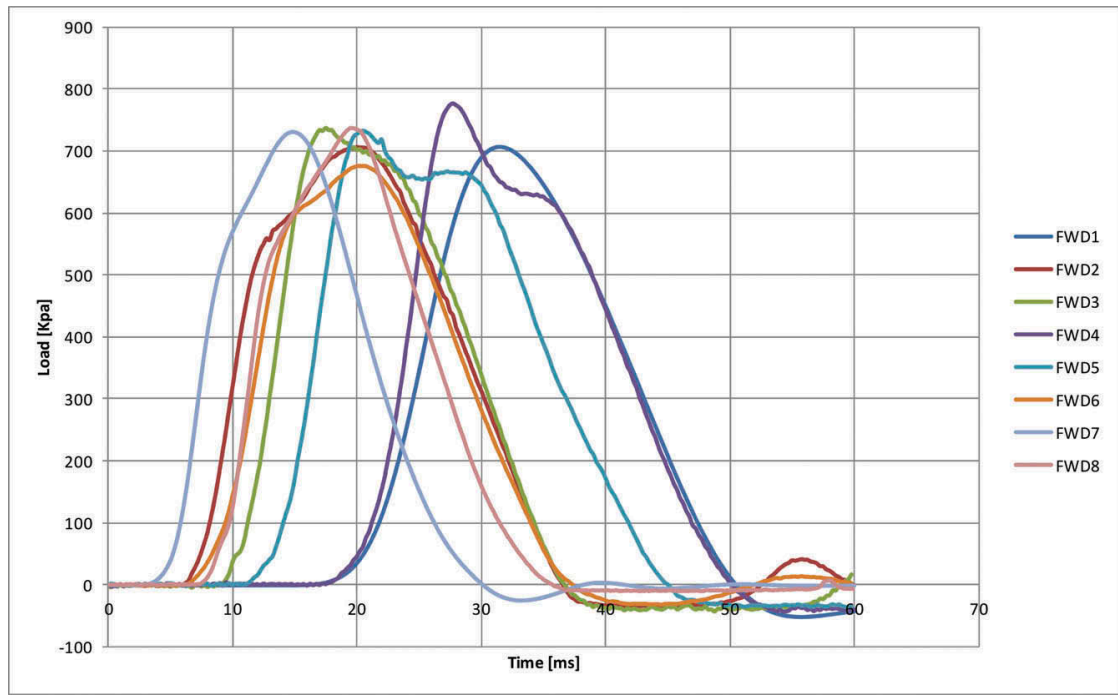

Figure 6. Load impulse history of several FWDs.

\subsection{Temperatures}

Calibration of the temperature sensors is usually not included in the annual FWD calibration services. Due to the high temperature dependence of the asphalt, the correct determination of the temperatures is very important. It was assumed that the measurement of temperatures is relatively simple and accurate. However, the experience of the last years shows that the correct measurement of temperatures is a big problem. 


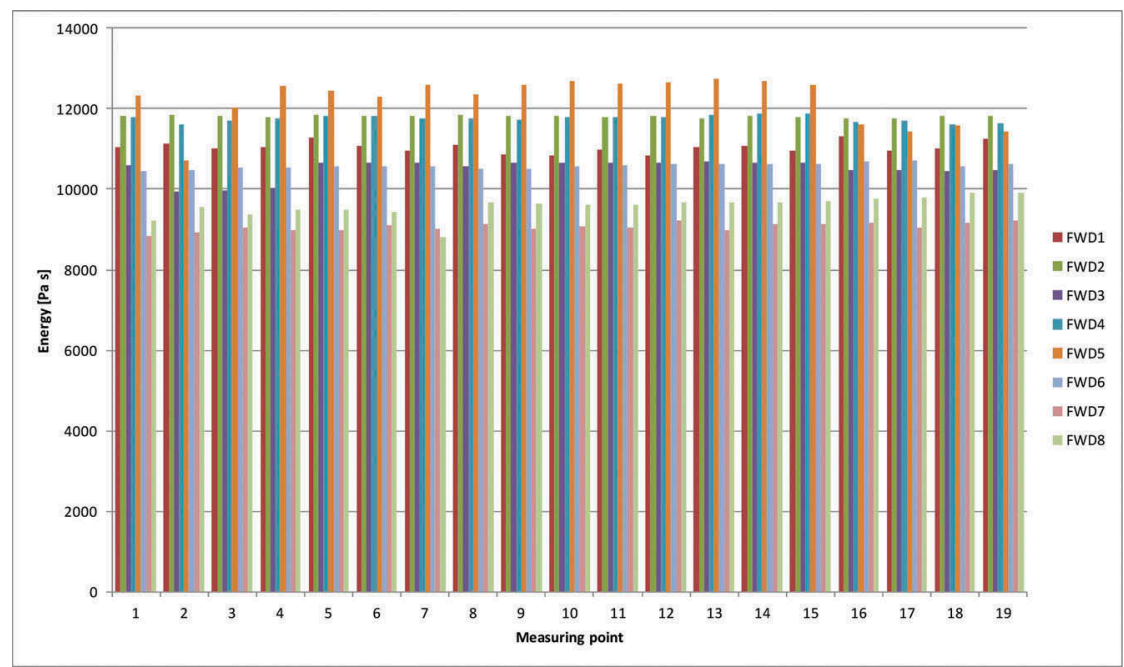

Figure 7. Calculated load impulse input as an integral over time of different FWDs.

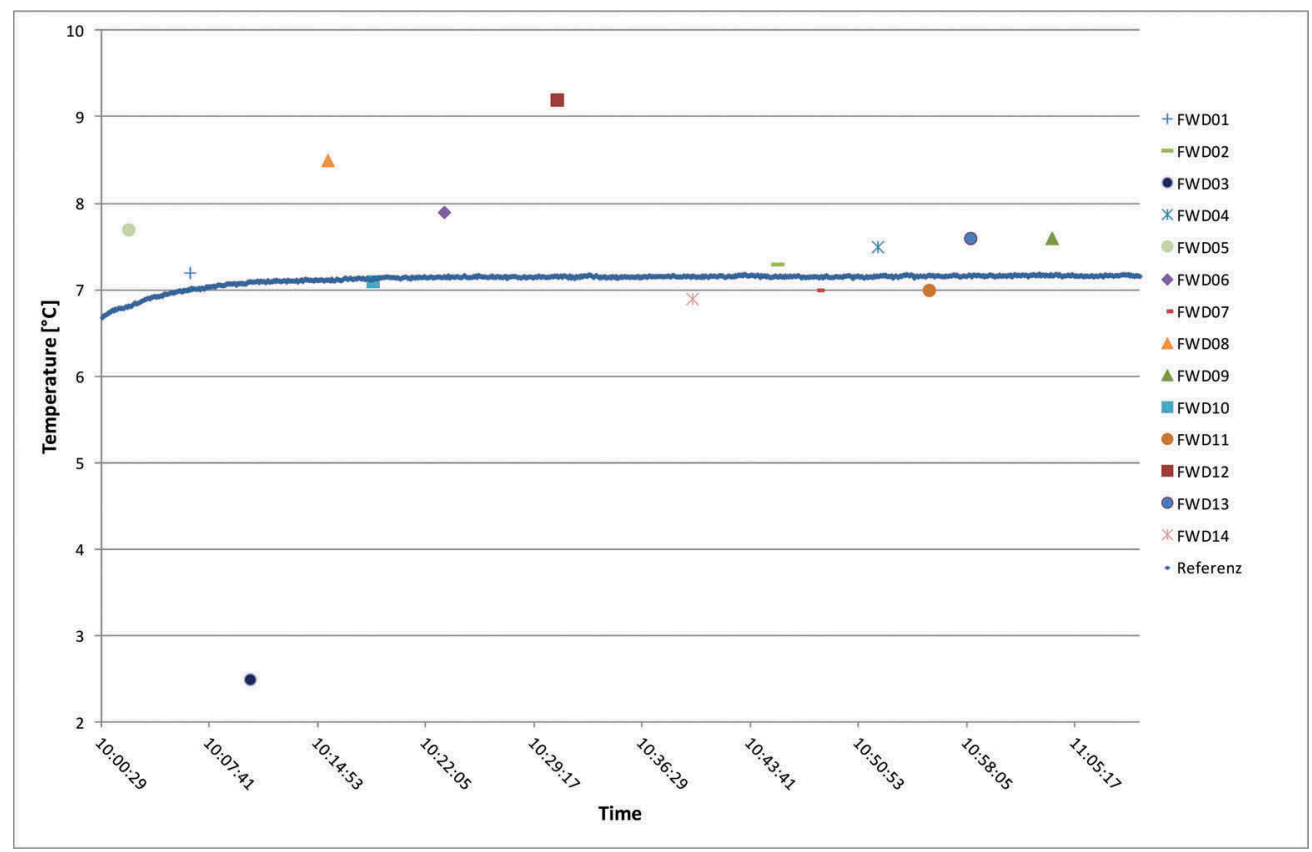

Figure 8. Comparison of the temperature measurement by FWD in a water bath (sensor for the asphalt body temperature measurement) and data logger (reference).

Both the alignment of some sensors in the water bath, as well as the comparison of the measured values of different FWD among themselves and in comparison to data of the meteorological station existing on the BASt premises show partly large and unsystematic deviations (Figure 8 and 9). Causes of errors could not be clarified conclusively so far. The reasons are assumed to be the installation positions of the 


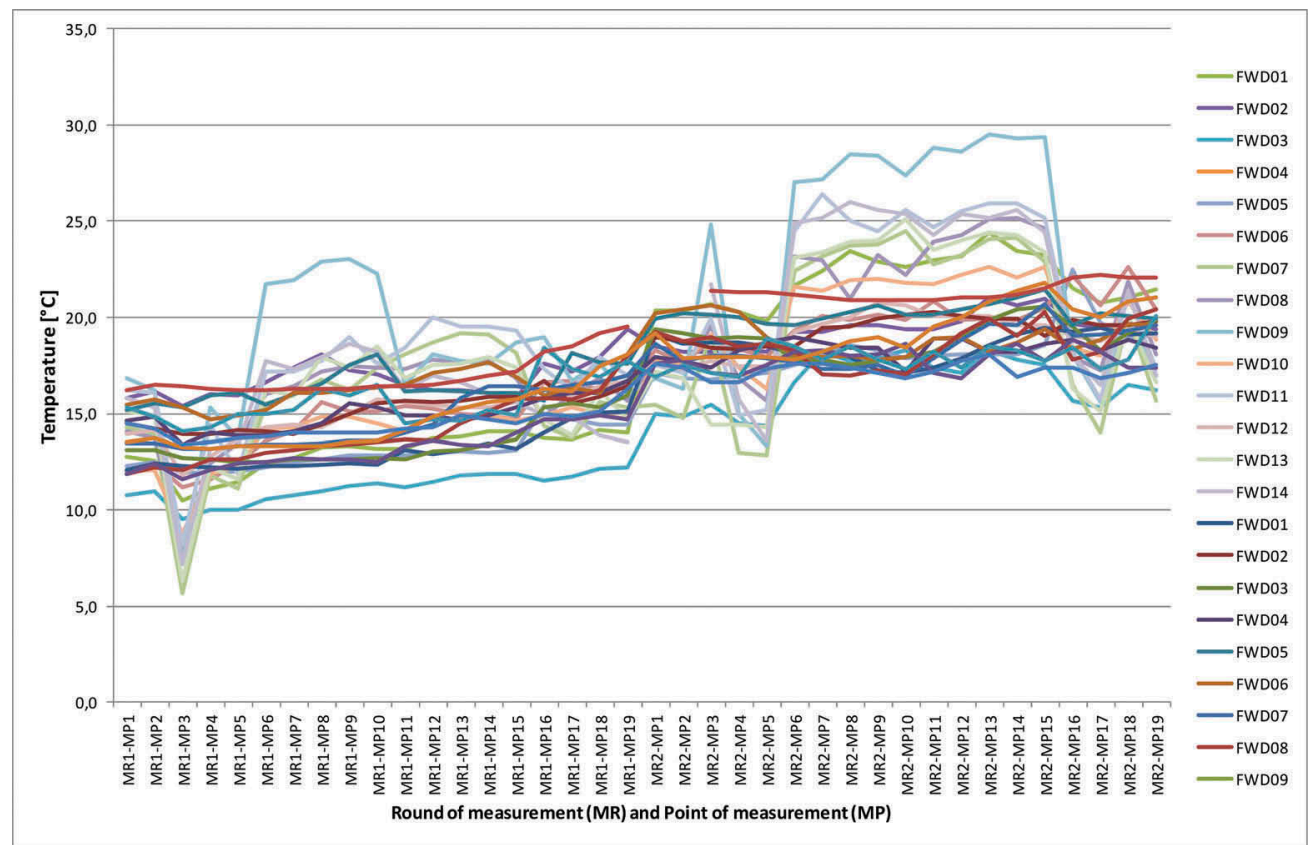

Figure 9. Comparative representation of the measured surface temperatures.

temperature sensors (e.g. near the exhaust system of in-built FWDs) and also the partly very short contact times during surface temperature measurement with contact thermometers.

\section{SUMMARY}

Bearing capacity measurements with the FWD must be carried out in a quality assured manner. This is the only way to ensure that a valid basis for decisions on maintenance management is available. The execution and evaluation of comparative measurements offers the possibility to test the entire measuring system under real conditions, i.e. also with the usual influences by the operator.

The results of the events carried out so far have shown that this method can clearly identify faults in the measurement vehicles. The results also show that the FWD method is a relatively robust method. Attention should be paid in the future to improve the temperature measurement. For this purpose, the support of the manufacturers is required.

The events carried out so far have met with great interest. The event has meanwhile established itself internationally and is usually held annually. On the client side, participation is increasingly desired or even demanded. In addition to the technical aspects, it has also become clear that the exchange of information between operators is an important element of quality assurance. For this purpose, the event offers a good platform in addition to the regular user group meetings, for example.

\section{REFERENCES}

European Commission, 2005. European Cooperation in the Field of Scientific and Technical Research, COST 336 „Use of Falling Weight Deflectometers in Pavement Evaluation”, Final Report, Brussels, Belgium. 
FGSV, 2008. Arbeitspapier Tragfähigkeit, Teil B2.1 „Falling-Weight-Deflectometer (FWD): Beschreibung, Messdurchführung - Asphaltbauweisen", FGSV-Verlag, Köln, Germany.

Straube, E., Beckedahl, H. \& Huertgen, H., 1996. Begleitende Forschung zur Einführung des Falling-WeightDeflectometer (FWD) in der Bundesrepublik Deutschland, Straßenbau und Straßenverkehrstechnik, Bonn, Germany.

Van Gurp, C., 2013. FWD Correlation Trial 2013. CROW report D13-05, Ede, Netherlands. 